\title{
Jean-Jacques Lemêtre e a presença da dramaturgia sonora no processo de criação do ator
}

\author{
ALEX BEIGUI PAIVA CAVALCANTE \\ FLÁVIA FERNANDES COUTO
}

Alex Beigui Paiva Cavalcante é artista-pesquisador, Pós-doutor em Dramaturgia pela Université de Lausanne - Suíça (bolsista CAPES), Doutor em Letras (Dramaturgia Comparada - Literatura Brasileira) pela USP (bolsista FAPESP), mestre em Artes Cênics pela UFBA. Professor Associado do Departamento de Artes da Universidade Federal do Rio Grande do Norte (UFRN).

AFILIAÇÃO: Universidade Federal do Rio Grande do Norte (UFRN) - Natal, RN - Brasil.

Flávia Fernandes Couto é atriz e pesquisadora, Bacharel em Artes Cênicas pela USP, com Habilitação em Interpretação Teatral, Mestre em Pedagogia do Teatro pela USP. AFILIAÇÃO: Universidade de São Paulo (USP) - São Paulo, SP - Brasil. 
- RESUMO

Neste artigo busca-se melhor compreender historicamente as relações entre a música e o corpo do ator como forma de tecnologia em andamento, presente em vários processos cênicos contemporâneos. Para tanto, destacamos o trabalho do francês Jean-Jacques Lemêtre, junto ao Théâtre du Soleil como campo e potencial qualitativo da investigação acerca da sonoridade e sua interação com o corpo em estado pré-expressivo (processo) e cênico (resultado). Destaca-se, ainda, a ideia da música como arquitetura do movimento, reivindicada em diferentes épocas, bem como as relações entre as imagens sonoras e as imagens corporais no repertório da cena contemporânea.

\section{PALAVRAS-CHAVE}

Música, ator, imagens sonoras, imagens corporais, dramaturgia.

\section{ABSTRACT}

This article aims for a better historical comprehension of the relationship between music and the actor's body as a technological ongoing form among many contemporary scenic processes. For this purpose, we highlight the work of Jean-Jacques Lemêtre in the Théâtre du Soleil as the key for the investigation about the sonority and its interaction with the (pre)scenic body. This work also highlights the idea of music as the motion architecture of a larger work of art reclaiming, at different times, the relationships between sound images and bodily images within the contemporary scene's repertory.

\section{KEYWORDS}

Music, actor, sound images, body images, dramaturgy. 


\section{Musicalidade no corpo e na cena: alguns pressupostos}

Nas duas últimas décadas do século $X X$, principalmente em processos criativos através dos quais a figura do ator/intérprete tornou-se o pilar central do processo de criação, muitos encenadores utilizaram a música como dispositivo fundante e vital na construção da relação entre o corpo e a mise en scène. Um dos procedimentos mais utilizados pelo compositor Jean-Jacques Lemêtre nos processo criativos do Théâtre du Soleil, por exemplo, é a composição musical ativa, que caminha concomitantemente com o trabalho criativo do intérprete. Sabe-se que a utilização do ritmo na elaboração do verso trágico é oriunda da tragédia ática e, talvez, mesmo antes dela, em cerimoniais litúrgicos, fortalecendo-se, séculos depois, com a concepção de "obra de arte total" de Richard Wagner, conhecida no mundo inteiro como gesamtkunstwerk.

A tragédia que advém do grego tragoidia (tragos: bode e oidé: canto), canto ao bode, é uma ode a Dionísio, confirmando - desde sua etimologia e da presença do canto no coro trágico - a relação indissociável entre a tessitura vocal e a poesia, o que inevitavelmente rompe com limites entre a voz falada e a voz cantada. JeanJacques Lemêtre afirma em seus estudos sobre a relação entre o corpo do ator e a música que não há distinção técnica entre voz falada e voz cantada na composição cênica, atribuindo ao grego clássico uma perfeita sintonia entre ritmo e sentido. Lemêtre chama atenção, ainda, para o fato de que no grego antigo, uma das línguas mais ricas em variações rítmicas do mundo, encontramos aproximadamente 534 variações, no português do Brasil cerca de 17 e no francês, a mais pobre entre elas, aproximadamente 4 variações ${ }^{1}$.

A utilização da música no âmbito da composição dramatúrgica, enquanto matriz cênica e eixo teatral, complexifica-se na contemporaneidade, sobretudo, em trabalhos de encenadores como Bob Wilson, Gerald Thomas, Peter Brook, Ariane Mnouchkine, Antônio Nóbrega; as montagens do grupo polonês Teatr Zar, do grupo catalão La Fura dels Baus, entre outros ${ }^{2}$. Dessa forma, observamos diversas linhas contemporâneas de processos estéticos e criativos, cuja criação teatral mantém diálogo e interface direta com a música em seus estados harmônicos e enarmôni$\cos ^{3}$. Uma dessas inúmeras possibilidades ocorre quando um tema musical ou uma atmosfera e/ou a paisagem sonora é amplamente pesquisada em todas suas potencialidades, conectando-se ao corpo do intérprete como modo de expansão e de

\footnotetext{
$\overline{1}$ No Master class realizado na escola Barco Virgílio em São Paulo em maio de 2013, Jean-Jacques Lemêtre ao falar sobre sua extensa pesquisa sobre a métrica e módulos rítmicos das línguas, afirma ser a métrica francesa a mais pobre de todas, com 4 variações e atribui ao grego antigo a mais rica. Em relação ao português ele atribui 17 variações, mas afirma que há um desacordo entre linguistas que dizem não existir métrica para a língua portuguesa.

2 Ao citarmos tais encenadores, apontamos e ressaltamos a importância de trabalhos brasileiros específicos que surgiram diretamente a partir da relação corpo/música/sonoridade/ritmo. São eles: Carmen com filtro o (1986), de Gerald Thomas, espetáculo que mantém intenso diálogo com a ópera de Bizet; Vau da Sarapalha (1992), de Luiz Carlos Vasconcelos, trabalho centrado na pesquisa sonora, assinada pelo percussionista e compositor Escurinho; Todas as horas do fim (1999) de Nadja Turenko, monólogo inspirado no universo musical de Janis Joplin; Ispiritulncarnadu (2001) de Celina Sodré, solo criado a partir das imagens sonoras em Guimarães Rosa; Medeia (2001) de Antunes Filho, trabalho onde o corpo é exposto como metáfora dos sons da natureza, de seus ruídos e variantes.

3 Utilizamos aqui o termo "enarmônico" para abranger os tipos de produção musical que se apropriam de ruídos, de acordes dissonantes e de modulações fora dos modos de entendimento lineares ou sequenciais tradicionalmente associados à musicalidade. Um bom exemplo desse tipo de composição está nas obras do compositor John Cage, sobretudo suas criações das décadas de 1970, 1980 e 1990.
} 
sinergia, o que intensifica e organiza as emoções do intérprete em estados cênicos e pré-expressivos.

Para Eugenio Barba, o treinamento condiciona o corpo do ator, visando um estado de presença e, sobretudo, de consciência entre os fluxos internos e externos. A ideia de um treinamento que ative princípios energéticos de presença está muito clara na concepção do teatro antropológico proposto pelo diretor do Odin Teatret. Para ele: "Estes princípios-que-retornam constituem a Antropologia Teatral como um campo da pré-expressividade." (Barba, 1994, p.25) . Entende-se por "dança pessoal" a escuta dos sons e sonoridades produzidos no e pelo corpo em estado de permanente experimentação e observação. É importante destacar que o treinamento não exclui a experimentação e a improvisação, mas, contrariamente, são a base para ambas.

Em importante estudo sobre a relação treinamento energético e a "dança pessoal", intitulado Diálogos entre o Butô e a dança pessoal, Erika Oliveira afirma:

Considero necessário esse tempo de pensamento sobre o "corpo em conflito" no Treinamento Energético, já que ele foi o responsável pelo surgimento da Dança Pessoal e pela descoberta das matrizes corpóreas, a partir dele. Após um tempo de experiências com o Treinamento Energético, é possível verificar que alguns movimentos retornam espontaneamente e a partir da recorrência de movimentos, o ator pode aos poucos codificar e nomear essas ações, construindo as matrizes de sua dança pessoal. (OLIVEIRA, 2009, pp. 37-38).

A "dança pessoal" conhecida também nas práticas corporais orientais como self coaching traz dois modos de atuação: o primeiro advém das espontaneidade do movimento e dos fluxos energéticos; o segundo, da codificação e da qualidade do movimento. O movimento externo surge dessa escuta interna produtora de ações rítmicas. Carlos Alberto Simioni, Ricardo Puccetti e Denise Garcia, sobretudo entre 1956 e 1995, sistematizaram e apoiaram o trabalho técnico que parte da escuta e observação do corpo dilatado do ator e de suas potências expressivas. Parte-se do treinamento energético, permitindo que cada ação criada tenha íntima relação com o ambiente sonoro, desdobrando-se muitas vezes em um treinamento sistemático entre o corpo, a ação, o som/ruído e o movimento que o corpo executa em estado de alerta.

Para melhor compreender a presença da dramaturgia sonora e da tecnologia musical no processo de criação do ator, faz-se necessário pontuar alguns aportes acerca da expertise corpo-música e do modelo de "valência afetiva" proposta por Russel ${ }^{4}$. Para os autores Danilo Ramos e José Lino Oliveira Bueno:

A valência afetiva (ou valor hedônico) é mensurada a partir da premissa de que toda música carrega em si um valor afetivo, que pode variar de pessoa para pessoa; podemos ficar em um determinado estado emocional durante uma escuta musical, dependendo de nossas diferenças individuais, oriundas de nossos diferentes valores culturais (adquiridos a partir do meio em que vivemos) e biológicos (ina-

\footnotetext{
$\overline{{ }^{4} \mathrm{~A} \text { temática }}$ do presente artigo teve como precedência a dissertação de mestrado da autora. Cf. BRUSADIN, Lia Sipaúba Proença. Os Cristos da Paixão da Ordem Terceira do Carmo de Ouro Preto (MG). 260 f. Dissertação (Mestrado em Artes) - Escola de Belas Artes, Universidade Federal de Minas Gerais, Belo Horizonte, 2014..
} 
tos, que se referem ao conteúdo genético transmitido de geração a geração). A valência afetiva, portanto, refere-se ao grau de satisfação desencadeado no ouvinte durante uma escuta musical (RAMOS; BUENO, 2012, p. 22).

A partir desse contexto, é possível pensar a música como tecnologia não só da cena, mas como componente técnico expressivo do corpo do intérprete e da qualidade de sua presença em cena, inclusive em relação ao espectador. Paralelamente à noção de "valência afetiva", proposta por Russell, é possível identificar não só a intensidade das emoções, mas alguns estados de excitação fisiológicos (elevado ou baixo) que a música produz. Para os dois especialistas acima citados:

O 'arousal' (ou estado de excitação fisiológica) é mensurado a partir da premissa de que toda escuta musical provoca no participante uma espécie de estado de pré-ativação interna, em que mecanismos neurais e cognitivos são ativados, levando o participante a prestar atenção à música que está sendo executada. O 'arousal' chega a provocar até mesmo reações motoras nos participantes, como bater o pé ou as mãos para imitar o acompanhamento da música, dançar, entre outros comportamentos. (RAMOS; BUENO, 2012, p.22)

$\mathrm{Na}$ relação de processos que envolvem a mistura de partituras musicais e partituras corporais nos processos de criação a partir do corpo do ator, percebemos que a presença das duas dimensões se complexifica à medida que as tensões corpo e sonoridade são exploradas concomitantemente, pois o diálogo entre o corpo e a música necessariamente perpassa pela dimensão criativa do intérprete, gerando uma espécie de dança pessoal, singular e intransferível. Essa ação afasta-se radicalmente da ideia de "composição coreográfica", fortemente marcada pela relação de submissão do gesto à música.

A dança pessoal, tal como vem sendo delineada no campo das artes cênicas, é um trabalho de leitura e de reescritura, ou seja, de uma dramaturgia que busca as mesmas qualidades de energia e de vibrações encontradas no campo energético dos atletas e das lutas marciais, alguns códigos semelhantes aprimorados no treinamento pessoal, mas com dinâmica completamente diversa. É mister fazer uma diferença, nesse contexto, entre performance e desempenho.

Nesse sentido, o treinamento energético trabalha em ritmo acelerado, visando ultrapassar o esgotamento físico, mas sem ter por meta a ideia de "desempenho" a ser superado, trata-se, ao contrário de uma ação-reação imediata, quase por reflexo, por meio da qual o agente da ação é impedido de efetuar ações simplistas de causa e efeito, evitando assim uma dramaturgia de resultado previsível.

\footnotetext{
${ }^{2}$ Camillo Boito (1836 - 1914) foi arquiteto, restaurador, crítico, historiador, professor, teórico e literato. Teve papel importante na transformação da historiografia da arte a na formação de uma nova cultura arquitetônica na Itália. Na restauração, apresentou uma posição moderada e intermediária entre Viollet-le-Duc (linha intervencionista), cujos preceitos seguiu durante muito tempo; e Ruskin (linha anti-intervencionista), sintetizou e elaborou os princípios que se encontram na base da teoria clássica da restauração.

3 Cesare Brandi (1906 - 1988) é um dos principais nomes da restauração de obras de arte. Tinha licenciatura em Direito e História da Arte, também atuou como poeta, escritor, pintor e professor de Hitória da Arte na Universidade de Roma. Foi diretor do Instituto Central de Restauração (ICR) de Roma, por duas décadas, desde sua fundação em 1939 até 1960. Coordenou a restauração de inúmeras obras de arte destruídas nos bombardeios da Segunda Guerra Mundial. Paralelamente, desenvolveu uma teoria da restauração em que delimita pressupostos que serviram de embasamento à prática do restaurador, aliando suas pesquisas teóricas nos campos da estética e da filosofia da arte com as práticas e experiências desenvolvidas no âmbito do ICR.
} 
Diferentemente do campo estético e poético, o treinamento do atleta, pautado, sobretudo, na ideia de superação e de competição trabalha com essas ações recorrentes, codificando-as e as aprimorando com vistas a um resultado e a uma meta previamente definida.

\section{Da escuta do ambiente à "dança pessoal"}

A "dança pessoal" trabalha com ações musicais recorrentes no corpo do intérprete, segundo às diversas qualidades subjetivas de energia do ator criador, usando diferentes dinâmicas, muitas vezes lentas e vagarosas, em que o objetivo, segundo Luís Otávio Burnier é: "ouvir-se, buscar e explorar formas de articulação, por meio do corpo, das energias potenciais que estão sendo dinamizadas." (BURNIER, 2001, p.140) ${ }^{5}$. Seguindo a estética proposta por Burnier, o trabalho de Simione com a "dança pessoal", em seu treinamento, contribuiu para a criação do espetáculo "Kelbilim, o cão da divindade" $(1998)^{6}$. O treinamento diário de Simioni permitiu nesse trabalho que ele codificasse uma série de matrizes de movimento e ações, com diferentes qualidades vibratórias e sonoras. $\mathrm{O}$ trabalho surgiu paulatinamente dessa investigação corporal do intérprete com a dramaturgia sonora e pessoal, resultado de um longo período de pesquisa, de observação e de escuta em cena.

Pode-se afirmar que o trabalho de Simioni navega entre dois extremos. De um lado, extremamente denso, evocando imagens sonoras de dor, gritos, berros intercalados com pausas silenciosas através do corpo; de outro, delicado, intimista, evocando imagens sonoras agudas e de fragilidade. Dessa maneira, essas oposições e duplicidades fizeram com que o tema escolhido oscilasse entre o grave e o agudo, construindo por meio das variações corpo/sonoridade ricas formas de expressividade. Assim, os textos escolhidos de Nietzsche, Hilda Hilst, São João da Cruz e principalmente Santo Agostinho passaram a ser submetidos à expertise corporal e à expertise musical do intérprete, ou ao que o próprio Simioni denominou de "canto de ações", gerando um tipo de "técnica", cujo "método" até hoje se mantém válido nas linhas de pesquisa desenvolvidas pelo Grupo LUME.

A presença de imagens sonoras, em grande parte advindas do repertório desses artistas da cena, comprova a interação corpo e música como parte fundamental de seus respectivos campos de investigação. Todavia, ainda que observemos a presença de pesquisa sobre sons e de utilização de imagens sonoras, constatamos a ausência de estudos mais sistemáticos, por parte da crítica especializada, ou seja, que pense a dramaturgia musical como forma de expansão do corpo no espaço da cena, através das múltiplas técnicas sonoras desenvolvidas ao longo do tempo.

Quando falamos de expansão do corpo no espaço cênico, queremos evidenciar que a relação entre imagem plástica e imagem sonora sempre esteve atu-

\footnotetext{
${ }^{5} \bar{E}$ importante citar como referência na criação desta técnica, além de Grotowski, a dança butoh, proposta por Tatsumi Hijikata e Kazuo Ohno, e o trabalho desenvolvido por Etienne Decroux sobre o "dínamo ritmo", que consiste na inter-relação da força, quantidade, duração e intensidade, ou seja, a musicalidade ou densidade musical do movimento. Sabe-se, a partir de relatos, que as aulas de Decroux eram todas cantadas, visando explorar as potencialidades musicais de cada movimento, ação e gesto.

${ }^{6}$ Esse trabalho foi o primeiro espetáculo do Grupo LUME, "Kelbilim, o cão da divindade" estreou em 1988, em um antigo convento de Campinas-SP, se apresentando em diversas cidades do Brasil, além da Itália, da Dinamarca, do Peru, da Grécia e do Equador.
} 
ando de modo indissociável na exploração de técnicas e tecnologias manipuladas na cena contemporânea. Sobre o assunto atesta Béatrice Picon-Vallin:

\begin{abstract}
Anos vinte, anos sessenta, anos oitenta: as imagens - projetadas, transmitidas e difundidas sobre a pequena tela, fixas ou animadas, em preto e branco ou em cores, documentais ou ficcionais, em salas de alta definição, analógicas ou digitais - serão complementadas em seguida com o material sonoro, continuando a se complexificar. $\mathrm{O}$ processo se acelera e se intensifica em conexão com o desenvolvimento e com a miniaturização dos equipamentos e aparelhos de imagem e de som, de difusão, de projeção, complementados e postos à prova por artistas engenheiros ou bricoleurs (PICON-VALLIN, 2004, p. 01, tradução nossa). ${ }^{7}$
\end{abstract}

É importante observar que as técnicas de atuação desenvolvidas ao longo dos diferentes períodos e escolas vão a partir dessas décadas e, mais especificamente na década de 1990, dialogar com os avanços tecnológicos, tendo como mídia principal o corpo do intérprete e seus modos de expansão no espaço e no tempo da cena.

A cena híbrida que o século XX anuncia e realiza não pode ser compreendida sem que pensemos a relação corpo-imagem, seja ela visual, tátil, virtual, muito menos sem que a pensemos em relação à dimensão das imagens sonoras envolvidas. A ideia de uma arte total, desde a ópera de Wagner, passando pelos processos de diálogos intensos entre o teatro, a fotografia e o cinema dos anos de 1930, de Erwin Piscator a Edward Gordon Craig, perpassa por uma arte dos sentidos que dialoga e se transforma de acordo com as técnicas e tecnologias do seu tempo. Movimento que inclui inevitavelmente o diálogo entre o corpo e a música.

A ideia de "obra de arte total" ressurge com muita força na década de 1950, sobretudo com Josef Svoboda e Jacques Poilieri que buscavam, já em 1958, uma "arte do movimento total", alicerçada, sobretudo, na ideia de interatividade/multimídia. Béatrice Picon-Vallin confirma:

É na Praga dos anos de 1958 que Josef Svoboda inventou as técnicas da "Lanterna Mágica", apresentada na exposição de Bruxelas, e mais tarde as do Polyécran. Ambas, por ele, aplicável ao teatro. "Lanterna Mágica" combina uma composição sincrônica, plástica e sonora com o jogo do ator ou bailarino, um cena cinética (com esteira, espirais), som estereofônico com telas móveis, e com o cinema e suas possibilidades de montagem e de aparelhamento. "Lanterna Mágica", cena multimídia e autônoma, apresentada no Teatro Nacional de Praga e "O circo encantador" (1977) tiveram mais de 2.500 apresentações. $^{8}$

\footnotetext{
${ }^{7}$ No original: "Années vingt, années soixante, années quatre-vingt: les images — projetées, diffusées sur grand puis/et sur petit écran, fixes ou animées, noir et blanc ou en couleurs, documents ou fictions, sales ou haute définition, analogiques, puis numériques - se sont faufilées, puis installées sur la scène, en même temps qu'une matière sonore qui va aller en se complexifiant. Le processus s'accélère et s'intensifie en liaison avec le perfectionnement et la miniaturisation des appareils de prises de vue et de son, de diffusion, de projection, complétés par les trouvailles spécifiques mises au point par des artistes ingénieurs ou bricoleurs.". (PICONVALLIN, 2004, p. 01).
} 
Apontamos registros dessas interações em uma tradição ocidental que atinge diretamente o modo de fazer teatro no Brasil por acreditar que a partir da década de 1960, sobretudo, com o advento dos estudos culturais, as relações e fronteiras entre localização, regionalização e universalização tornaram-se cada vez menos demarcadas e territorializadas do ponto de vista estético e político. Dessa maneira, torna-se importante investigar os modos como a música e a pesquisa sonora se apresentam enquanto forma de interação corpo/cena.

Nesse sentido, chamamos atenção para a pesquisa corpo/música/sonoridades realizada por Jean-Jacques Lemêtre junto ao Théâtre du Soleil, sobretudo, por ela se apresentar como expoente nos estudos que envolvem as técnicas contemporâneas, os procedimentos e as tecnologias na ação criativa do intérprete.

O trabalho do Théâtre du Soleil com Lemêtre, nessa linha, vem sendo uma referência extremamente importante, pois a música em seus processos de criação surge concomitantemente com a encenação e com o jogo de ação dos atores. Uma criação simultaneamente individual e coletiva, autoral e colaborativa.

Em ambas as perspectivas de criação (individual e colaborativa) o que está em jogo é sempre a valorização da fisicalidade como modo de alcançar um estado de presença, menos intelectivo do ponto de vista da escrita cênica e mais experiencial do ponto de vista do corpo sonoro em estado cênico e mesmo pré-expressivo. ${ }^{9}$

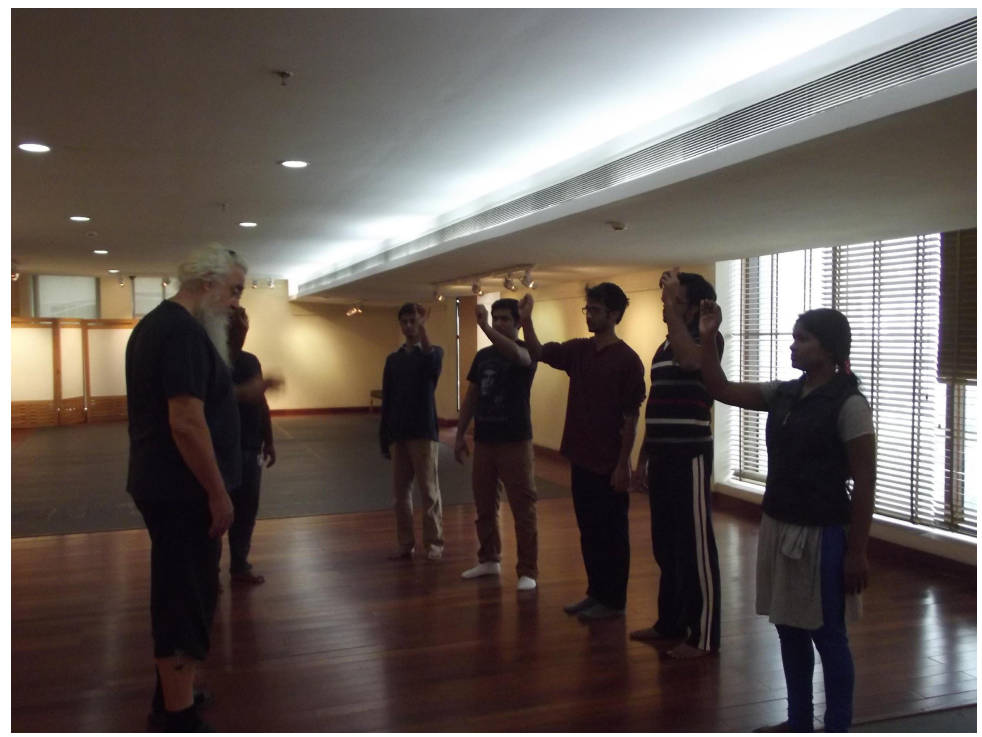

Figura 01: Lemêtre em processo de composição, corpo e voz. ${ }^{10}$

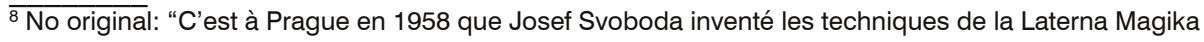
présentée à l'exposition de Bruxelles, et plus tard celles du Polyécran. II les appliquera au théâtre. La Laterna magika combine dans une composition synchrone, plastique et sonore, le jeu de l'acteur ou du danseur, la scène cinétique (tapis roulant, tournettes), le son stéréophonique, les écrans mobiles, et le cinéma, avec ses possibilités de montage et de truquage. A la Laterna Magika, scène multimédia rattachée au Théâtre national de Prague avant de devenir autonome, Le Cirque enchanteur (1977) sera représenté plus de 2500 fois." . (PICONVALLIN, 2004, p. 03)

${ }^{9}$ É importante lembrar que Stanislavski foi o primeiro a sistematizar a diferenciação entre ação dramática e ação física. A primeira sempre relacionada, no decorrer dos estudos teatrais, ao texto dramático, à noção de personagem, de conflito e de drama, seguindo a lógica aristotélica de uma estrutura que divide o texto dramático em unidades de ação, tempo e espaço, através das quais se manifestam as personagens. Já a noção de "ação física" defendida e diferenciada por Stanislavski preconiza, estabelece e inaugura no ocidente uma nova corrente de pensamento sobre composição de personagem, propondo como texto paralelo às ações corporais do ator em cena.

${ }^{10} \mathrm{~A}$ utilização de todas as imagens neste artigo foi gentilmente autorizada por Jean-Jacques Lemêtre.
} 


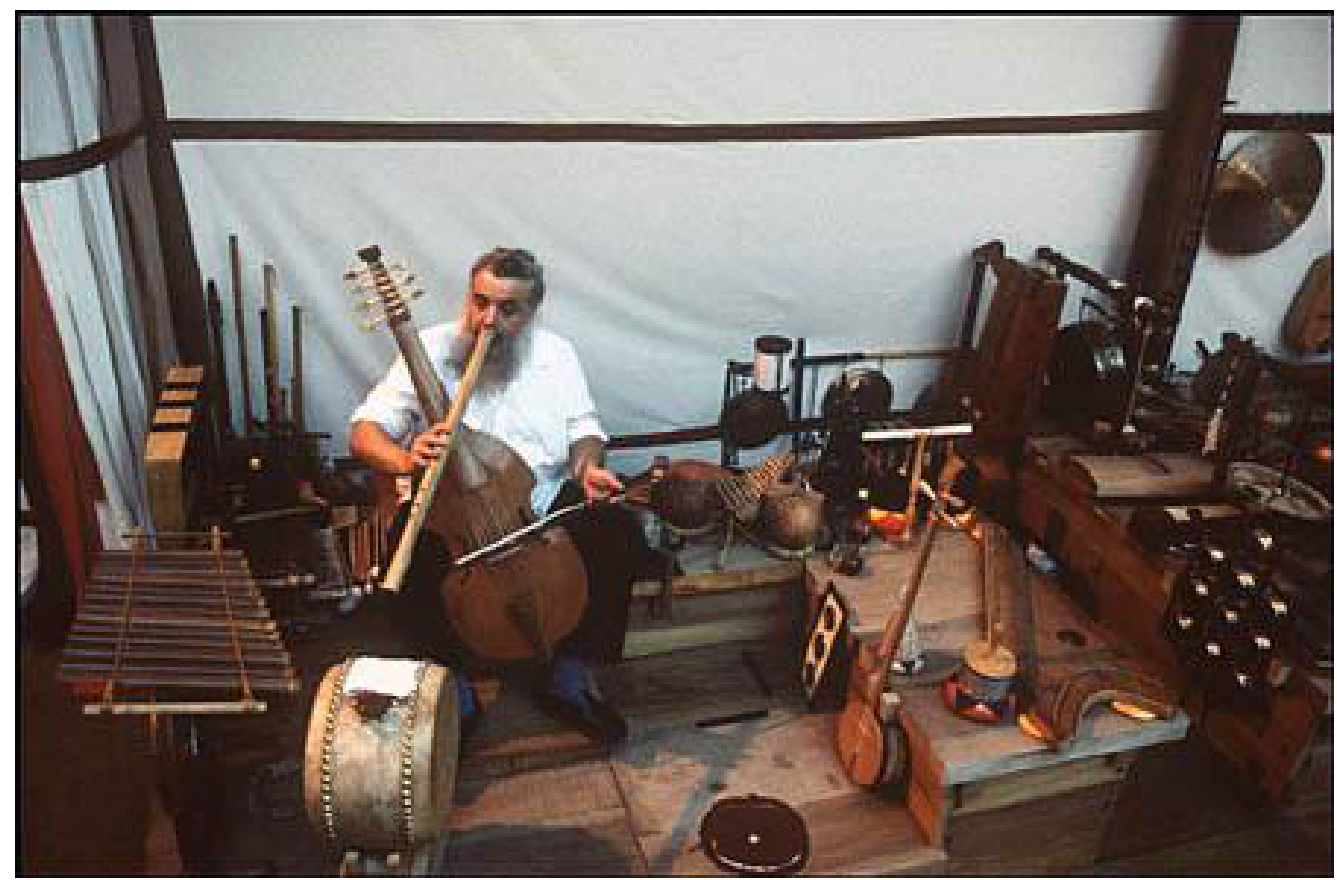

Figura 02: Lemêtre em seu espaço de experimentação e de criação de sonoridades

Acreditamos que tais explorações e campos de investigação revelam-se como dispositivos importantes na investigação entre voz e corpo, som e movimento, simetria e assimetria, bem como na observação das aliterações que envolvem o campo de pesquisa do intérprete nas artes cênicas. Ao inserir a música em seus processos investigativos, Lemêtre desenvolve um aprimoramento técnico do intérprete e de suas potencialidades criativas. Nesse, sentido, o trabalho dele parece explorar ao máximo essa linha de composição entre dispositivo corporal e dispositivo sonoro, através da experimentação e da escuta de materiais linguísticos, rítmicos e laborais.

É a partir do final da década de 1970 e início dos anos de 1980 que a parceria entre Lemêtre e Ariane Mnouchkine acontece e se intensifica de modo mais sistemático. A complexidade do processo composicional entre a encenadora, o músico e os atores ganha, paulatinamente, uma metodologia própria. Desde "Mephisto" (19791980), "Les Shakespeare" (1981-1984), "L'histoire terrible mais inachevée de Norodom Sihanouk, roi du Cambodge" (1985-1986), "L'Indiade ou I'Inde de leurs rêves" (1987-1988), a presença de Lemêtre ganha destaque por afetar diretamente o sistema rítmico de movimentação do ator em cena e por oferecer tecnicamente um conjunto de imagens sonoras em permanente diálogo com as imagens visuais da cena.

Se em encenadores como Robert Wilson, a participação do músico é de fundamental importância para o resultado do trabalho, como é o caso do já citado "Sonnets Shakespeare" (2009), em Ariane Mnouchkine essa relação se produz e acontece durante todo o processo de composição, havendo assim uma interação direta músico/ator/encenadora. Em espetáculos como "Les Atrides" (1990-1993), "La ville parjure ou Le Réveil des Érinyes" (1994-1995), "Le tartuffe" (1995-1996), "Soudain des nuits d'éveil" (1997-1998), percebemos o fortalecimento do vínculo composicional e criativo entre o trabalho musical e o desenho plástico da cena. 


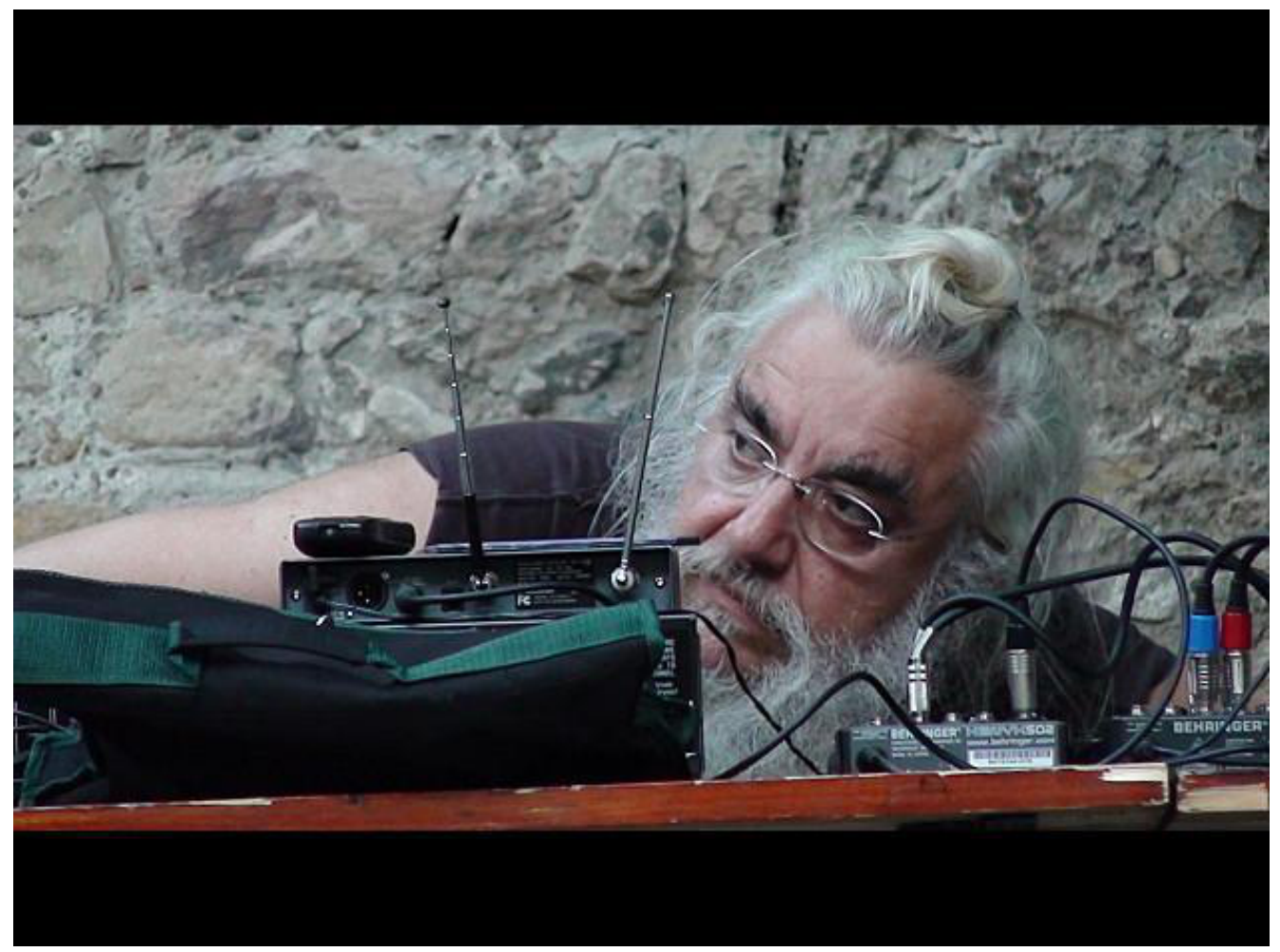

Figura 03: Lemêtre à escuta do material plurilinguístico coletado.

A cinestesia corporal provocada pela exploração da música e de seus efeitos sonoros no corpo do intérprete assume a tônica dos trabalhos realizados em parceria entre Mnouchkine e Lemêtre e dos processos de criação que compõem o rico repertório do Théâtre du Soleil.

O trabalho da dança pessoal, enquanto registro de uma partitura de ações físicas do ator em estados extra quotidianos, é bem fundamentado na também investigação de Grotowski, que buscava o que ele denominava de "transe" ou "transiluminação" do ator. Eugênio Barba inclusive dedica o livro La terra di cenere e diamante: II mio apprendistato in Polonia (1998)11 à descrição de sua rica experiência com Grotowski. A intensa pesquisa de Grotowski, continuada depois por Thomas Richards, baseava-se na exploração das plenas potências físicas e vocais dos atores, utilizando-se muitas vezes de músicas e de mantras em seu treinamento. No Teatr Zar ${ }^{12}$, na Polônia, por exemplo, com a pesquisa e assimilação de cânticos sagrados que antecedem qualquer trabalho de composição cênica, percebemos a transformação e a ênfase do olhar para a relação do teatro oriental e seus modos de organização rítmica.

O olhar para o oriente que tanto inquietou homens de teatro tão diferentes como Bertolt Brecht e Antonin Artaud, em meados do século XX, começa a encontrar os elos de exploração, aproximação e aprendizado mútuos, através da explora-

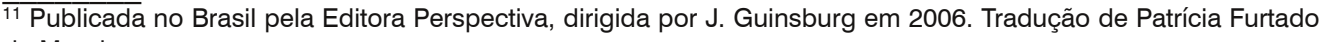
de Mendonça.

12 "Zar" é o nome de canções de funeral da tribo Svaneti que habitam as altas regiões do Caucasus, no noroeste da Geórgia.
} 
ção da música em seus distintos modos de manifestação. A própria utilização da máscara no teatro grego, como forma de ampliação da caixa de ressonância vocal dos atores, parece comprovar a importância milenar da voz e dos diversos tipos de dramaturgia sonora na poética cênica.

No espetáculo "Anhelli" $(2009)^{13}$, por exemplo, do grupo polonês citado anteriormente, toda a encenação foi fundamentada na música (mantra de cânticos armênios), que após anos de pesquisa e bem executados pelos atores, serviram como matriz de composição de toda a dramaturgia corporal e encenação do espetáculo. ${ }^{14}$

Em "Anhelli", os atores se revezam e alternam suas funções em cena, como intérpretes e cantores, o espetáculo exige uma presença focada primordialmente no trabalho do "ator-musical" e na projeção das imagens sonoras para o público, seguindo assim a linha do "teatro pobre" de Jerzy Grotowski e as correntes que exploram, sobretudo, o campo energético provocado pela relação corpo e música.

A música e o texto corporal, nesta linha de trabalho, são justapostos desde o processo embrionário de criação, o que não significa dizer que são submetidos, hierarquicamente, um ao outro. Daí fica evidente nos mais recentes trabalhos de Jean-Jacques Lemêtre junto aos atores de Mnouchkine, como "Les Naufragés du Fol Espoir" (2010-2012) e "Macbeth" (2014), o sistema de criação colaborativa. A sincronização tem a ver com os estágios de interação do corpo, da voz e da música em cena, explorados por Lemêtre; seguidos da amplificação sensorial do campo energético e motor da cenografia construída pela Cartoucherie.

\section{Considerações finais}

No trabalho do Théâtre du Soleil, podemos observar a importância da composição musical como parte do processo criativo e composicional do ator, onde ele é instigado sempre a criar "camadas" e "paisagens" para as propostas de cena e para sua efetiva realização. A experimentação ocorre desde a fabricação de instrumentos até a investigação idiomática. Em Lemêtre, o intérprete é convidado a experimentar a escuta sobre si mesmo, a investigar a sonoridade do seu próprio corpo-vocabulário como ressonância ampliada e amplificadora do som no ambiente.

Nunca é demais esclarecer que nos processos criativos contemporâneos essas relações entre a atividade interna e a atividade externa correspondem a espaços de organização do corpo com o seu ambiente. $\quad 0$ corpo corresponde, no palco, a uma arquitetura de composição, sua eficácia se desloca do campo da técnica vocal como artificialização para o campo de seus desvios estruturantes e de seus diferentes modos em lidar com o ambiente e com o material de origem, a saber: o corpo, a voz e as sonoridades.

A encenadora Ariane Mnouchkine sempre propõe ao ator encontrar uma música interior, mas não psicologizante; uma música que encontre a sinfonia de su-

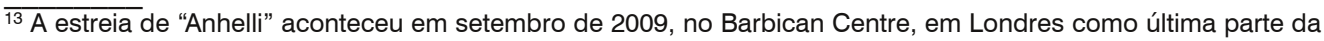
trilogia realizada pelo Grupo Gospels of Childhood.

${ }_{14}$ O processo de experimentação e criação do Grupo Teatr Zar dá continuidade aos estudos de Grotowski e faz referência, também, às origens do teatro nas tragédias gregas, na presença musical do coro, revelando a indissociável relação entre o canto, a voz e o ritmo na tessitura do texto. O processo de investigação do grupo polonês se realiza a priori sobre a música instrumental de tradição asiática. O Teatr Zar segue sua linha de pesquisa em cantos polifônicos, algo marcante na Tragédia Grega ática e também na formas tradicionais do teatro oriental Nô, Kabuki e Kathakali.
} 
as emoções ao longo do processo de criação, porém emoções no sentido físico, sensorial. Em seus processos, a atividade do compositor Lemêtre é de criar juntamente com o ator uma relação de mão-dupla, e também triangular, incluindo o encenador, onde todos são compositores, criadores e agentes da ação. Como aponta Picon-Vallin em recente estudo, ainda não publicado no Brasil, sobre os cinquenta anos do Théâtre du Soleil:

Mnouchkine insiste para seus atores: sem ilustrações. Eles serão ajudados pela música. A música extravasa cada comportamento, ela cria uma transposição artística, fazendo de cada deslocamento uma espécie de dança, diferente para cada um - pequenos passos percussivos de Cambojanos com suas saias apertadas, não as marteladas militares... Ela acompanha as entradas e saídas dos personagens, se cola a caminhada de cada um, ela assegura como um tapete voador, e cava as 'grandes entradas' e 'grandes saídas' dos políticos que invadem ou saem do palco com uma nuvem de conselheiros. Em função das necessidades que há para acompanhar a cena e os personagens, Lemêtre inventa instrumentos, e os refaz, os transformando levemente; eles são fabricados aos seus cuidados, pelos estagiários ou membros da trupe e sua coleção aumenta. Ele procura os timbres para os personagens, como em uma gravura fabricada em uma máscara filipina, ele quer uma música teatral, não uma música cambojana." (PICONVALLIN, 2014, p. 168, tradução nossa)..$^{15}$

É importante ressaltar que em tais processos de criação há sempre um dialogismo cultural presente. O processo envolve uma postura consciente de apropriação cultural, a partir da qual o corpo do intérprete está situado, localizado, identificado com as paisagens sonoras criadas. As marcas culturais dos corpos são reagrupadas e induzidas a se relerem através da estética cênica proposta pela encenadora.

A música no processo de criação de Lemêtre é sempre relacional, dentro desta tríade ator-compositor-encenador, ela é presença e dramaturgia, apresentando-se muitas vezes como a própria arquitetura do texto cênico, uma vez que desenha e processa concretamente algo que se passará na cena posteriormente. A música cria uma palheta de cores ${ }^{16}$ que convoca, libera, ultrapassa e controla a gama de sensações do ator em cena.

\footnotetext{
${ }_{15}$ No original: Mnouchkine insiste auprès des comédiens : pas d'illustration. Ils seront en cela aidés par la musique. La musique " étragéise " chaque comportement, elle crée la transposition artistique, faisant de chaque déplacement une sorte de danse, différente pour chacun et chacune - petits pas trottinants des Cambodgiennes dans leurs jupes serrées, pas martelés des militaires... Elle accompagne entrées et sorties des personnages, se coule dans la démarche de chacun, qu'elle soutient comme un tapis volant, et scande les " grandes entrées » et « grandes sorties » des hommes politiques qui envahissent ou quittent le plateau avec une nuée de conseillers. En fonction des besoins qu'il a pour accompagner les scènes ou les personnages, Lemêtre invente des instruments, en fait refaire en les transformant légègerement ; ils sont fabriqués par ses soins, par des luthiers ou des membres de la troupe et sa collection a augmenté. II cherche des timbres pour les personnages, comme avec le kotoportrait fabriqué dans un masque philippin, il veut une musique théâtrale, pas une musique cambodgienne. (PICON-VALLIN, 2014, p. 168).

16 "Palheta de cores" é o termo usado por Lemêtre para designar essa criação que potencializa a multiplicidade de camadas no trabalho de construção do corpo do ator e da encenação em conjunto com a música, no sentido de ampliar possibilidades e não reduzi-las a imagens meramente figurativas.
} 
A música nunca é colocada em jogo uníssono com as emoções do ator, ao contrário, ela é sempre dissonante, polifônica, cria camadas, gerando outras ações para além da proposta inicial. Essas ações que sobram podem ser vistas no contexto da música como ruídos da criação. Como já assinalamos, O trabalho na Cartoucherie envolve a construção de instrumentos musicais originais e o mapeamento de línguas e variações linguísticas de diferentes culturas. Ao longo de 15 anos, Lemêtre registrou 1800 línguas e dialetos do mundo inteiro, por meio dos quais ele compôs uma sinfonia de línguas, distribuída no repertório de 45 horas de vozes faladas de todo o mundo, e a partir da qual ele orquestrou a fim de criar uma experiência multissensorial, inteiramente realizada no espetáculo "Babel Orkestra" (2012). ${ }^{17}$

Podemos concluir que Lemêtre realiza um trabalho de (des)ornamentação e desnudamento do caráter doutrinário da música frente ao corpo do intérprete, apostando nos elementos cognitivos do ator. Em seus processos, percebemos que a vertente teórica dialoga diretamente com a vertente empírica a partir de uma abordagem etnometodológica de caráter fortemente experimental: múltiplas vozes, múltiplos corpos, múltiplos sons, múltiplos movimentos. A investigação interativa proposta por Lemêtre merece destaque nos estudos que envolvem as novas formas técnicas e as tecnológicas do fazer cênico dentro de novos agenciamentos interativos, pois seus procedimentos apontam para uma prática que emerge de diferentes mecanismos de validação da qualidade expressiva em cena.

Em seus trabalhos junto ao Théâtre du Soleil evidenciamos, ainda, o entrecruzamento de estruturas cognitivas, relacionais, motoras, emocionais e rítmicas, cuja finalidade é desenvolver uma dramaturgia sonora fincada nas potencialidades do som e do comportamento sonoro do intérprete.

\section{Referências}

BARBA, Eugênio. A canoa de papel. São Paulo: Hucitec, 1994.

BURNIER, Luís Otávio. A arte do ator: da técnica à representação. Campinas, SP: Editora da Unicamp. 2001.

GALVÃO, Alfredo. Cognição, emoção e expertise musical. Psicologia: Teoria e Pesquisa, Brasília, n. 02, vol. 22, 2006, pp. 169-174.

GROTOWSKI, Jerzy. Em busca de um teatro pobre. Rio de Janeiro: Civilização Brasileira. 1987.

KENNY, Don. Kyogen book: an anthology of japanese classical comedies. Tokyo: Japan Times, 1989.

LALLIAS, Jean-Claude. La musique du ver à soie (rencontre avec Jean-Jacques Lemêtre). Théâtre du Soleil, 2003. Disponível em: http://www.theatre-du-soleil.fr/thsol/a-propos-du-theatre-du-soleil/la-musique,284/la-musique-du-ver-a-soie?lang=fr. Acesso em: 15/set./2015.

\footnotetext{
17 "Babel Orkestra" teve sua estreia mundial em Montreal em 2012. O poema sinfônico foi acompanhado das instalações da artista plástica Marcelle Hudon e com cardápio especial do concurso de criação culinária, visando uma experiência multissensorial.
} 
NIETZSCHE, Friedrich. O nascimento da tragédia. São Paulo: Companhia das Letras 2007.

OLIVEIRA, Erika. Diálogos entre o Butô e a Dança Pessoal. Dissertação de Mestrado, Programa de Pós-Graduação em Artes-Unicamp. Campinas-SP, 2009.

PICON-VALLIN, Béatrice. Le Théâtre du Soleil: les cinquante premières années. Paris: Actes Sud, 2014.

Les avant gardes théâtrales et les technologies de leur temps. Création numérique, les nouvelles écritures scénique. Paris: Programme international de Rencontres et de Recherche Arts de la Scène et Nouvelles Technologies, 2004, pp. 01-05. Disponível em http://www.scenes-digitales.info. Acesso em 18/set./2015.

RAMOS, Danilo; BUENO, José Lino Oliveira. A percepção de emoções em trechos de música ocidental erudita. Per Musi, Belo Horizonte, n.26, 2012, pp. 21-30.

RICHARDS, Thomas. $\quad$ At work with Grotowski on physical actions. New York: Routledge, 1995.

ROMANO, Lúcia. O teatro do corpo manifesto: teatro físico. São Paulo, Editora Perspectiva, 2005.

ROSS, Alex. O resto é ruído: escutando o século XX. Trad. Ivan Weisz Kuck. São Paulo: Companhia das Letras, 2009

SCHERER, Jacques. Bharata, la création du théâtre, bouffonneries, théâtres d'orient, le kathakali, l'odissi. Théâtre du Soleil, $n^{\circ} 9$, traduction du premier chapitre du Natya Sastra, 1983. Disponível em: http://www.theatre-du-soleil.fr/thsol/sources-orientales/les-sources-orientales/inde/bharata-lacreation-dutheatre?lang=fr. Acesso em: 15/set./2015.

SOARES, Marília V. Técnica energética: fundamentos corporais de expressão e movimento criativo. Tese de Doutorado, Programa de Pós-Graduação em Artes - Unicamp. Campinas-SP, 2004.

Recebido em 24/10/2017 - Aprovado em 12/08/2018.

Como citar:

BEIGUI, Alex; COUTO, Flávia. Jean-Jacques Lemêtre e a presença da dramaturgia sonora no processo de criação do ator. ouvirOUver; Uberlândia, v.14.n.2, p 482-495, jul./dez. 2018. Disponível em: http://www.seer.ufu.br/index.php/ouvirouver; DOI: http://doi.org/10.14393/OUV23-v14n2a2018-16 